\title{
Thermal stability of reactive sputtered tungsten oxide coatings
}

\author{
N.M.G. Parreira, T. Polcar, A. Cavaleiro* \\ ICEMS-Grupo de Materiais e Engenharia de Superficies, Faculdade de Ciências e Tecnologia da Universidade de Coimbra-Pólo II-Pinhal de Marrocos, \\ 3030-788 Coimbra, Portugal
}

Received 10 November 2006; accepted in revised form 5 January 2007

Available online 17 January 2007

\begin{abstract}
The thermal stability of different $\mathrm{W}-\mathrm{O}$ coatings, $\mathrm{W}_{100}, \mathrm{~W}_{90} \mathrm{O}_{10}, \mathrm{~W}_{54} \mathrm{O}_{46}, \mathrm{~W}_{30} \mathrm{O}_{70}$ and $\mathrm{W}_{25} \mathrm{O}_{75}$, were studied by in-situ $\mathrm{X}$-ray diffraction at elevated temperatures up to $900{ }^{\circ} \mathrm{C}$. The coatings were deposited by DC reactive magnetron sputtering from a pure tungsten target in an $\mathrm{Ar}+\mathrm{O}_{2}$ atmosphere onto Fecralloy alloy. The evolution of the structure of the coatings was studied in both protective and oxidant atmospheres. Three groups of films were identified: (1) $\mathrm{W}_{25} \mathrm{O}_{75}$ which showed structural evolution following the $\mathrm{W}-\mathrm{O}$ phase diagram; (2) amorphous O-deficient $\mathrm{WO}_{3}$ whose structure followed the $\mathrm{W}-\mathrm{O}$ phase diagram either as $\mathrm{WO}_{3}$ or as its chemical composition depending on annealing in oxidant or protective atmospheres, respectively; and (3) low O-content crystalline films that oxidized from $500{ }^{\circ} \mathrm{C}$.
\end{abstract}

(C) 2007 Elsevier B.V. All rights reserved.

Keywords: Tungsten oxide; Reactive sputtering; Structural characterization; Thermal stability

\section{Introduction}

Tungsten oxide is a very important semiconductor material. It has been found to have great application as an electrochromic device [1], as a semiconductor gas sensor [2] or for use in catalytic activity [3] as confirmed by the great number of publications in the field. However, the majority of these studies dealt with tungsten trioxide, while sub-stoichiometric tungsten oxides have not been yet intensively studied. Moreover, tungsten is one possible material for the inner wall of a fusion reactor [4].

In the $\mathrm{W}-\mathrm{O}$ phase diagram [5] the most important monophase regions are $\alpha-\mathrm{W}, \mathrm{WO}_{2}$ and $\mathrm{WO}_{3}$ corresponding to three oxidation states of tungsten, $\mathrm{W}, \mathrm{W}^{4+}$ and $\mathrm{W}^{6+}$ [6]. There are also many phases with chemical compositions between $\mathrm{WO}_{2}$ and $\mathrm{WO}_{3}$, such as $\mathrm{W}_{18} \mathrm{O}_{49}, \mathrm{~W}_{24} \mathrm{O}_{68}, \mathrm{~W}_{\mathrm{n}} \mathrm{O}_{3 n-2}$ and $\mathrm{W}_{n} \mathrm{O}_{3 n-1}$ [5]. $\mathrm{WO}_{3}$ itself is known as a polymorphous material that can exist as a function of the temperature, as triclinic, monoclinic, orthorhombic and tetragonal forms [7]; moreover, a hexagonal form can be synthesized under special conditions [8]. With low

\footnotetext{
* Corresponding author. Tel.: +351239790 745; fax: +351239790701.

E-mail address: albano.cavaleiro@dem.uc.pt (A. Cavaleiro).
}

oxygen content, a metastable $\mathrm{W}$ phase, known as $\beta$-W but also attributed to $\beta-\mathrm{W}_{3} \mathrm{O}$, can also be observed [9].

Among many deposition processes of tungsten oxides, reactive sputtering is one of the most versatile. Metastable structures can be easily deposited with this method, such as supersaturated solid solutions of oxygen in the $\alpha-\mathrm{W}$ phase, nanocrystalline or amorphous phases, as reported in a previous author's work [10]. In that study, W-O coatings were deposited and structurally characterized at room temperature. The structure of the coatings could be divided into four distinct zones: i) crystalline films with oxygen in solid solution in the b.c.c. $\alpha-\mathrm{W}$ or f.c.c. $\beta-\mathrm{W}\left(\right.$ or $\left.\beta-\mathrm{W}_{3} \mathrm{O}\right)$ phases [for oxygen content lower than 30 at.\%]; ii) in the range of oxygen from 30 up to 67 at.\%, the coatings were amorphous; iii) a transition region with a quasi-amorphous structure was defined in the range $[67$ at. $\%<0<75$ at.\%]; and iv) $\mathrm{WO}_{3}$ nanocrystalline structure was observed in the case of the coatings with compositions close to that of stoichiometric $\mathrm{WO}_{3}$. All the coatings with oxygen content higher than 30 at. $\%$ exhibited short-range order and, thus, it would be important to investigate their crystallization temperature. On the other hand, all coatings deficient in oxygen should, in a normal atmosphere, incorporate oxygen to reach stoichiometric composition. Therefore, knowledge of the structural evolution 
and the oxidation of $\mathrm{W}-\mathrm{O}$ coatings at elevated temperatures could be important for many applications. For instance in tribological applications at elevated temperatures, W-based coatings gain importance once they can form $\mathrm{WO}_{3-x}$, a phase belonging to the group of the "Magnéli-phases" which are known to perform as solid lubricants [11].

The aim of this investigation is to study the thermal stability of $\mathrm{W}-\mathrm{O}$ thin films deposited by $\mathrm{DC}$ reactive magnetron sputtering with a broad range of oxygen content, in normal and protective environments in order to distinguish the oxidation and crystallization phenomena. The analysis of the coatings is focused mainly on the structural changes during in-situ X-ray diffraction at elevated temperatures.

\section{Experimental details}

Using an industrial prototype DC reactive sputtering machine, $2.5 \mu \mathrm{m}$ thick tungsten oxide coatings were deposited onto polished Fecralloy $\left(\mathrm{Fe}_{73} \mathrm{Cr}_{22} \mathrm{Al}_{5}\right)$ alloy from a pure tungsten target $(150 \times 150 \mathrm{~mm})$ in a pure $\mathrm{Ar}-\mathrm{O}_{2}$ atmosphere. The pressure of argon was kept constant at $0.2 \mathrm{~Pa}(12.5 \mathrm{sccm})$, while $\mathrm{O}_{2}$ flow varied from 0 to $20 \mathrm{sccm}$, which give rise to a partial pressure of $\mathrm{O}_{2}$ in the range [0-0.28 Pa]. The deposition time was adjusted from 8 to $20 \mathrm{~min}$, according to previous experiences, in order to keep the final thickness approximately constant at $2.5 \mu \mathrm{m}$.

The deposition parameters were as follows: target current density $J_{\mathrm{W}}=6 \mathrm{~mA} \mathrm{~cm}{ }^{-2}$, inter-electrode distance of $65 \mathrm{~mm}$, substrate bias of $-70 \mathrm{~V}$, no substrate rotation and pumping speed $S=100 \mathrm{l} \mathrm{s}^{-1}$. Before deposition, an ultimate vacuum pressure lower than $3 \times 10^{-4} \mathrm{~Pa}$ was reached and the substrate surface was ion cleaned with an ion gun. The cleaning procedure included a first electron heating, up to temperatures close to $400{ }^{\circ} \mathrm{C}$ and, afterwards, an $\mathrm{Ar}^{+}$bombardment for $8 \mathrm{~min}$ (ion gun settings at $20 \mathrm{~A}, 40 \mathrm{~V}$ and substrate at $-100 \mathrm{~V}$ ).

The chemical composition of the coatings was determined by a Cameca SX-50 electron probe microanalysis apparatus (EPMA) and the structure of the films was analysed by X-ray diffraction (XRD) using a Philips diffractometer with $\mathrm{Co}-\mathrm{K} \alpha$ radiation in Bragg-Brentano configuration. The XRD equipment was provided with a high temperature chamber consisting of a platinum filament where the samples were attached using conductive glue. In this way the samples could be heated up to $1200{ }^{\circ} \mathrm{C}$ and in-situ annealed at high temperature. In the latter case, before introducing gas, the chamber was pumped down

Table 1

Influence of the oxygen flow rate on the total pressure, potential, chemical composition and deposition rate of the tungsten oxide coatings

\begin{tabular}{|c|c|c|c|c|c|c|}
\hline Sample & $\begin{array}{l}f \mathrm{O}_{2} \\
(\mathrm{sccm})\end{array}$ & $\begin{array}{l}p_{\text {total }} \\
(\mathrm{Pa})\end{array}$ & $\begin{array}{l}\text { Potential } \\
\text { (V) }\end{array}$ & $\begin{array}{l}\text { W } \\
\text { (at.\%) }\end{array}$ & $\begin{array}{l}\mathrm{O} \\
\text { (at.\%) }\end{array}$ & $\begin{array}{l}\mathrm{DR} \\
(\mathrm{nm} / \mathrm{s})\end{array}$ \\
\hline $\mathrm{W}_{100}$ & 0 & 0.20 & 405 & 99.5 & 0.5 & 2.0 \\
\hline $\mathrm{W}_{90} \mathrm{O}_{10}$ & 5 & 0.21 & 488 & 90.2 & 9.8 & 2.1 \\
\hline $\mathrm{W}_{54} \mathrm{O}_{46}$ & 10 & 0.23 & 554 & 53.9 & 46.1 & 2.2 \\
\hline $\mathrm{W}_{37} \mathrm{O}_{63}$ & 14 & 0.25 & 616 & 36.9 & 63.2 & 3.2 \\
\hline $\mathrm{W}_{30} \mathrm{O}_{70}$ & 16 & 0.28 & 646 & 29.4 & 70.6 & 4.4 \\
\hline $\mathrm{W}_{27} \mathrm{O}_{73}$ & 17 & 0.32 & 658 & 27.1 & 72.9 & 5.4 \\
\hline $\mathrm{W}_{25} \mathrm{O}_{75}$ & 20 & 0.48 & 578 & 25.5 & 74.5 & 2.3 \\
\hline
\end{tabular}

until a vacuum better than $10^{-3} \mathrm{~Pa}$ was reached. The XRD analysis was performed in room (air with relative humidity $\sim 50 \%$ ) and protective $\left(\mathrm{Ar}+\mathrm{H}_{2}\right)$ atmospheres. The XRD patterns were fitted using a Voigt function permitting several characteristics, such as the peak position $(2 \theta)$, the peak intensity and the full width at half maximum (FWHM) to be determined. The identification of the diffracted phases in the XRD patterns was done by comparing the position of the peaks with those of standard phases existing in the International Centre for Diffraction Data (ICDD) database [12].

\section{Results and discussion}

\subsection{As-deposited coatings}

The deposition parameters and the chemical compositions of tungsten oxide coatings are summarized in Table 1. As the oxygen flow increased from 0 to $17 \mathrm{sccm}$, the total pressure, target potential, oxygen content and deposition rate (DR) progressively increased from 0.2 to $0.32 \mathrm{~Pa}$, from 405 to $658 \mathrm{~V}$, from 0 to $\approx 73$ at. $\%$ and from 2.0 to $5.4 \mathrm{~nm} / \mathrm{s}$, respectively. For $20 \mathrm{sccm}$ the oxygen flow of the total pressure jumped to $0.48 \mathrm{~Pa}$, the target potential decreased down to $578 \mathrm{~V}$, the amount of oxygen in the coating slightly increased to 74.5 at.\% and the deposition rate decreased to $2.3 \mathrm{~nm} / \mathrm{s}$, as a consequence of target poisoning, as described elsewhere [13].

\subsection{Structural evolution}

Bearing in mind the achievements of previous research [10], from all the deposited coatings (Table 1) only some of them, gathered in three groups, were selected for the structural characterization at elevated temperature, according to their composition and structure at room temperature:

i) the $\mathrm{W}_{25} \mathrm{O}_{75}$ coating, since no further oxygen incorporation is possible and only phase transformations were expected;

ii) two amorphous coatings at room temperature, $\mathrm{W}_{54} \mathrm{O}_{46}$ and $\mathrm{W}_{30} \mathrm{O}_{70}$, which were analysed in protective atmosphere to analyse crystallization, and in air to investigate the incorporation of the oxygen in the coating and consequent formation of new phases;

iii) the crystalline $\mathrm{W}_{100}$ and $\mathrm{W}_{90} \mathrm{O}_{10}$ coatings, which were analysed only in oxidant atmosphere since these coatings already exhibited crystalline phases at room temperature, $\alpha-\mathrm{W}$ and a mixture of $\alpha-\mathrm{W}$ and $\beta-\mathrm{W}\left(\beta-\mathrm{W}_{3} \mathrm{O}\right)$, respectively.

The other coatings were not studied since $\mathrm{W}_{27} \mathrm{O}_{73}$ exhibits the same structure as $\mathrm{W}_{30} \mathrm{O}_{70}$ and $\mathrm{W}_{25} \mathrm{O}_{75}$ coatings at room temperature and $\mathrm{W}_{37} \mathrm{O}_{63}$, which exhibits a structure similar to the $\mathrm{W}_{33} \mathrm{O}_{67}$ coating of Ref. [10] at room temperature, and is expected to evolve according to the trends of $\mathrm{W}_{30} \mathrm{O}_{70}$ and $\mathrm{W}_{54} \mathrm{O}_{46}$ coatings.

\subsubsection{Coating $\mathrm{W}_{25} \mathrm{O}_{75}$}

The structural evolution of the $\mathrm{W}_{25} \mathrm{O}_{75}$ coating with increasing temperature is shown in Fig. 1. This coating has $\mathrm{WO}_{3}$ 


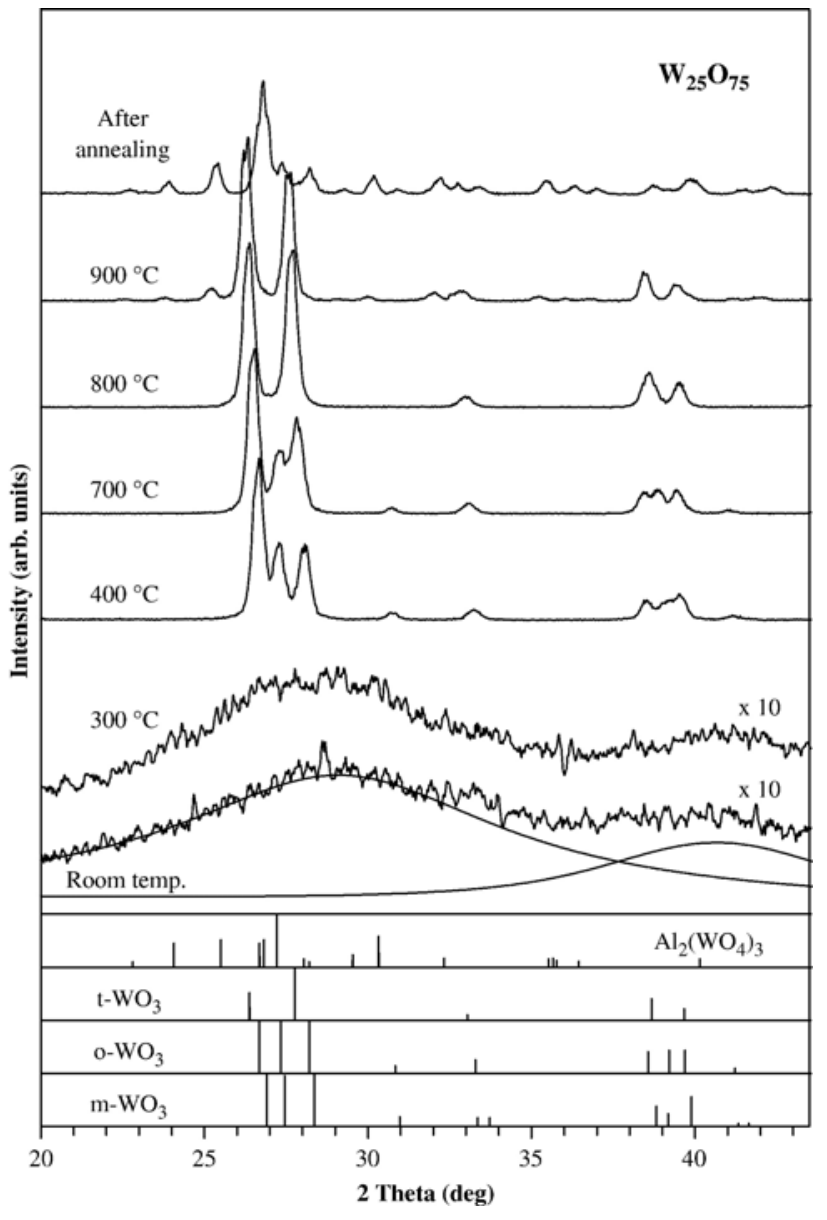

Fig. 1. In situ XRD diffractograms of $\mathrm{W}_{25} \mathrm{O}_{75}$ coatings taken at different temperatures in normal atmosphere.

stoichiometric composition and, thus, only thermal transformations are expected due to the highest oxidation level of W-metal. According to the phase diagram [5], the structure evolution for this chemical composition should be as follows: monoclinic from room temperature up to $330{ }^{\circ} \mathrm{C}$, orthorhombic between 330 and $740{ }^{\circ} \mathrm{C}$ and, finally, a tetragonal structure up to $1230{ }^{\circ} \mathrm{C}$. Due to the high level of energy involved in reactive magnetron sputtering, this method can easily lead to metastable structures [14] as demonstrated in this case, since this coating exhibited a quasi-amorphous structure. Applying a peak deconvolution and Scherrer equation to the broad peaks placed at $2 \theta$ between 25 and $35^{\circ}$ and $2 \theta$ between 35 and $45^{\circ}$, it is possible to affirm that the coherent domain of diffraction has values close to $1 \mathrm{~nm}$. The mean position of these peaks was calculated, close to $2 \theta=29.1$ and $40.7^{\circ}$, range of $2 \theta$ where a concentration of the main diffraction peaks of crystalline orthorhombic and tetragonal planes of $\mathrm{WO}_{3}$ were placed (ICDD cards nr. 71-0131 and 85-0807, respectively). No significant variation was visible up to $300{ }^{\circ} \mathrm{C}$, with the exception of a small shift in the peaks' positions to 28.5 and $41.9^{\circ}$, respectively, which is probably related to the dilatation induced by the temperature.

At $400{ }^{\circ} \mathrm{C}$ the coating crystallized in the orthorhombic structure, which remained up to $700{ }^{\circ} \mathrm{C}$. The analysis of these phases in the range between 25 and $30^{\circ}$ permitted three peaks corresponding to (002), (020) and (200) plans to be detected. The evolution of the lattice parameters, $a, b$ and $c$, of this structure between 400 and $700{ }^{\circ} \mathrm{C}$, calculated using the equation [15]:

$\frac{1}{d^{2}}=\frac{h^{2}}{a^{2}}+\frac{k^{2}}{b^{2}}+\frac{l^{2}}{c^{2}}$

where $d$ is the interplanar distance, and $h, k$ and $l$ are the Miller indexes, is shown in Fig. 2. An increase in the parameters $a$ and $c$ can be observed, which agrees well with the expansion induced by the heating of the coating; however, the value of the parameter $b$ remained almost unchanged. In spite of the similar intensity of all three peaks according to the ICDD card nr. 71-0131, a strong orientation following the (002) plan is detected. With increasing temperature the intensity of the (020) plan progressively decreases whereas those of the (200) plan increases.

At a temperature of $800{ }^{\circ} \mathrm{C}$, the structure transformed into the tetragonal phase. For the two main peaks, (001) and (110), in the diffraction region of $2 \theta=25-30^{\circ}$, a good correlation with the orthorhombic structure $\left(\mathrm{o}-\mathrm{WO}_{3}\right)$ could be found, as can be concluded from the extrapolation of the interplanar distances of the (002) and (200) from 400 to $700{ }^{\circ} \mathrm{C}$, to the positions of plan (001) and (110) of the tetragonal structure at $800^{\circ} \mathrm{C}$, in Fig. 2.

At $900{ }^{\circ} \mathrm{C}$, new peaks could be detected in the XRD pattern, corresponding to tungstate phases $\mathrm{A}_{2}\left(\mathrm{WO}_{4}\right)_{3}(A=\mathrm{Fe}, \mathrm{Cr}$ or $\mathrm{Al})$ [16] as a consequence of the inter-diffusion of elements ( $\mathrm{Fe}, \mathrm{Cr}$ and $\mathrm{Al}$ ) between the film and the substrate. The most probable element for $\mathrm{A}$ is aluminium $\left(\mathrm{Al}_{2}\left(\mathrm{WO}_{4}\right)_{3}\right.$, ICDD card nr. 81-2415) since, according to Tolpygo et al. [17], at $1000^{\circ} \mathrm{C}$ only $\alpha-\mathrm{Al}_{2} \mathrm{O}_{3}$ is observed during the oxidation of $\mathrm{Fe}-\mathrm{Cr}-\mathrm{Al}$ alloys. That means that at high temperatures, aluminium should enrich the substrate's surface closest to the coating. In fact, when one of these samples was oxidized up to $1300^{\circ} \mathrm{C}$, at the end of the test only $\mathrm{Al}$ and $\mathrm{O}$ were found on the surface by $\mathrm{EDX}$, since all the $\mathrm{WO}_{3}$ oxide had sublimated from $1000{ }^{\circ} \mathrm{C}$ on [5].

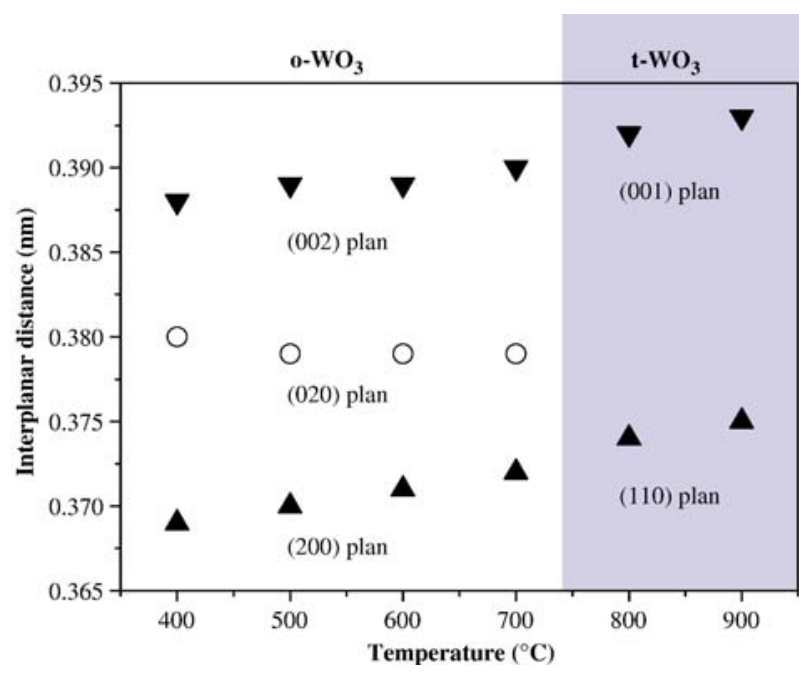

Fig. 2. Evolution of the interplanar distance of the planes placed between $2 \theta=25$ and $30^{\circ}$ of the $\mathrm{W}_{25} \mathrm{O}_{75}$ sample. According to the ICDD database the interplanar distance of the (200), (020) and (002) plans of the $0-\mathrm{WO}_{3}$ structure are 0.36705 , 0.37850 and $0.38770 \mathrm{~nm}$, respectively; and the interplanar distance of the (110) and (001) plans of the $\mathrm{t}-\mathrm{WO}_{3}$ structure are 0.37278 and $0.39200 \mathrm{~nm}$, respectively. 
After heating at $900{ }^{\circ} \mathrm{C}$, the sample was cooled down to room temperature leading to the transformation of the tetragonal phase in monoclinic $\mathrm{WO}_{3}$ structure $\left(\mathrm{m}-\mathrm{WO}_{3}\right.$, ICDD card nr. 830950). The tungstate phases remained visible.

\subsection{2. $W_{54} O_{46}$ and $W_{30} O_{70}$ coatings analysed in protective atmosphere}

The structural evolution of $\mathrm{W}_{30} \mathrm{O}_{70}$ and $\mathrm{W}_{54} \mathrm{O}_{46}$ coatings analysed in protective atmosphere is shown in Fig. 3. At room temperature, as shown in previous work [10], these samples exhibit a quasi-amorphous structure with a coherent domain of diffraction close to $1-1.2 \mathrm{~nm}$. However, they have a different short-range organization: the sample $\mathrm{W}_{30} \mathrm{O}_{70}$ has a similar structure to the $\mathrm{W}_{25} \mathrm{O}_{75}$ sample, with two broad peaks centred in positions close to 30 and $40^{\circ}$ whereas the $\mathrm{W}_{54} \mathrm{O}_{46}$ coating only exhibits one broad peak centred at $2 \theta=45.2^{\circ}$, which could be attributed to the position of the (110) $\alpha-\mathrm{W}$ line [10].

There was no transformation of the structure in protective atmosphere up to $600{ }^{\circ} \mathrm{C}$; at $700{ }^{\circ} \mathrm{C}$, the quasi-amorphous structure of these samples started to crystallize according to the phase diagram and their composition. The sample $\mathrm{W}_{30} \mathrm{O}_{70}$ crystallized in a mixture of $\mathrm{WO}_{2}$ and $\mathrm{W}_{18} \mathrm{O}_{49}$ and did not undergo any further transformation up to $900{ }^{\circ} \mathrm{C}$; moreover, the structure remained the same after cooling down to room temperature. The $\mathrm{W}_{54} \mathrm{O}_{46}$ sample, at $700{ }^{\circ} \mathrm{C}$, exhibited a

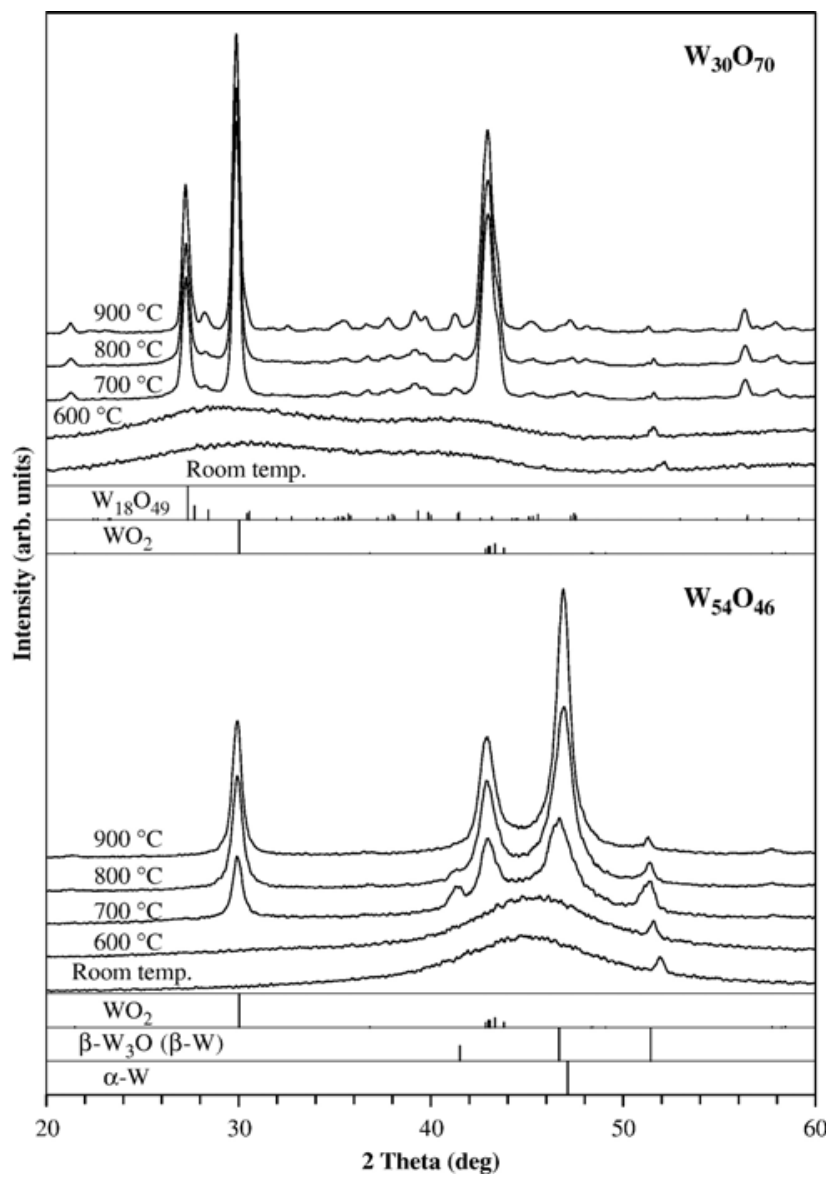

Fig. 3. XRD patterns of $\mathrm{W}_{30} \mathrm{O}_{70}$ and $\mathrm{W}_{54} \mathrm{O}_{46}$ samples at different temperatures in protective atmosphere.

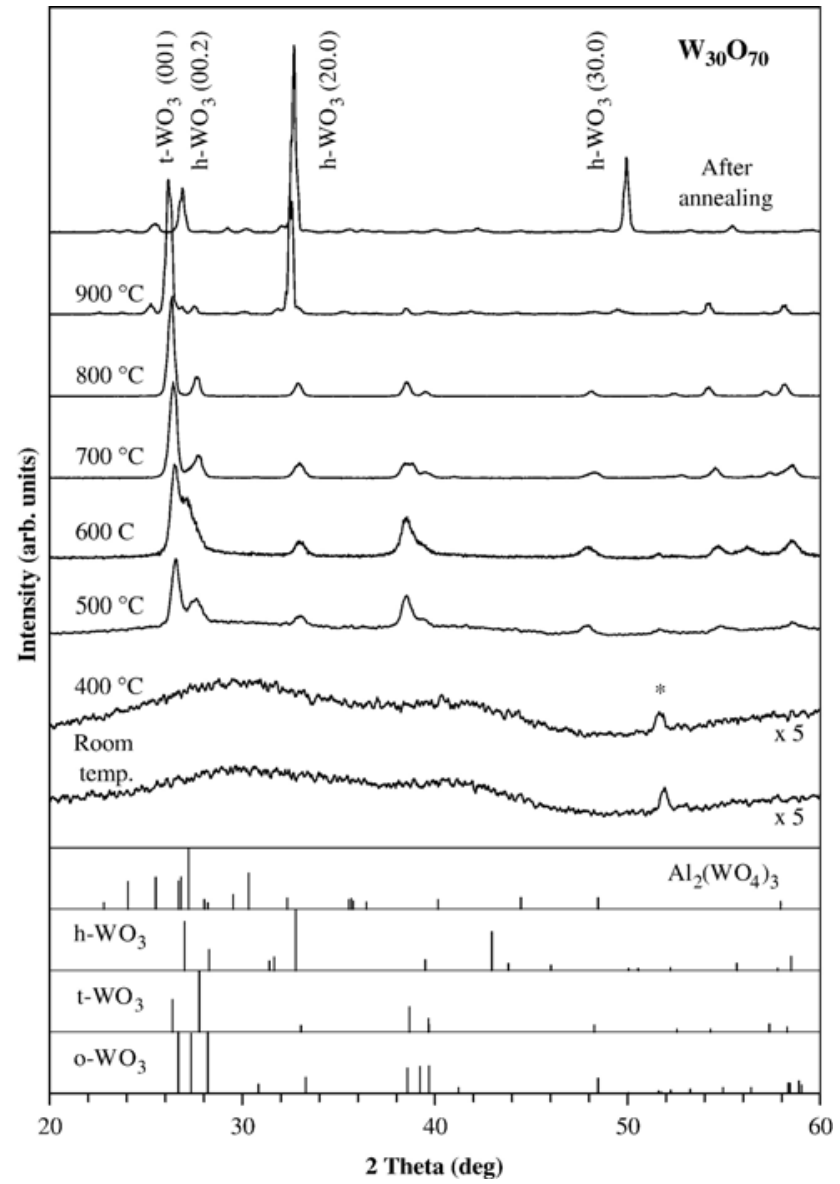

Fig. 4. Structural evolution of $\mathrm{W}_{30} \mathrm{O}_{70}$ coating as a function of the temperature. The measurements were done at normal atmosphere.

mixture of a residual amorphous part and a crystalline part (composed of $\mathrm{WO}_{2}$ and $\beta-\mathrm{W}_{3} \mathrm{O}$ ). The $\beta-\mathrm{W}_{3} \mathrm{O}$ is unstable at this temperature and was dissociated into $\alpha-\mathrm{W}$ and $\mathrm{WO}_{2}$ at $900{ }^{\circ} \mathrm{C}$ [9]. Also the amorphous part was reduced. Consequently, the structure of $\mathrm{W}_{54} \mathrm{O}_{46}$ after annealing at $900{ }^{\circ} \mathrm{C}$ in protective atmosphere was composed of $\alpha-\mathrm{W}$ and $\mathrm{WO}_{2}$.

\subsection{3. $\mathrm{W}_{54} \mathrm{O}_{46}$ and $\mathrm{W}_{30} \mathrm{O}_{70}$ coatings analysed in room atmosphere \\ $\mathrm{W}_{54} \mathrm{O}_{46}$ and $\mathrm{W}_{30} \mathrm{O}_{70}$ samples were also submitted to a} similar annealing cycle in room atmosphere as sample $\mathrm{W}_{25} \mathrm{O}_{75}$, see Figs. 4 and 5. Up to $400{ }^{\circ} \mathrm{C}$, the structural evolution of these coatings is similar to that in protective atmosphere. However, oxide diffraction peaks close to $2 \theta \approx 26-28^{\circ}, 33^{\circ}$ and $38-40^{\circ}$, started to appear at $500{ }^{\circ} \mathrm{C}$. Between $500{ }^{\circ} \mathrm{C}$ and $600{ }^{\circ} \mathrm{C}$ the coatings were composed of a mixture of amorphous and $\mathrm{W}-$ Oxides. Using the peak deconvolution to describe the XRD pattern at 500 and $600{ }^{\circ} \mathrm{C}$ for both samples, the area of the amorphous part corresponds to $66 \%$ and $11 \%$ for the sample $\mathrm{W}_{30} \mathrm{O}_{70}$ and $77 \%$ and $23 \%$ for the sample $\mathrm{W}_{54} \mathrm{O}_{46}$ at 500 and $600{ }^{\circ} \mathrm{C}$, respectively, see Fig. 6 . This apparent increase in the stability of the quasi-amorphous part for the low oxygen coating is a result of the higher absolute intensity of the quasiamorphous structure at room temperature of the coating $\mathrm{W}_{54} \mathrm{O}_{46}$. 


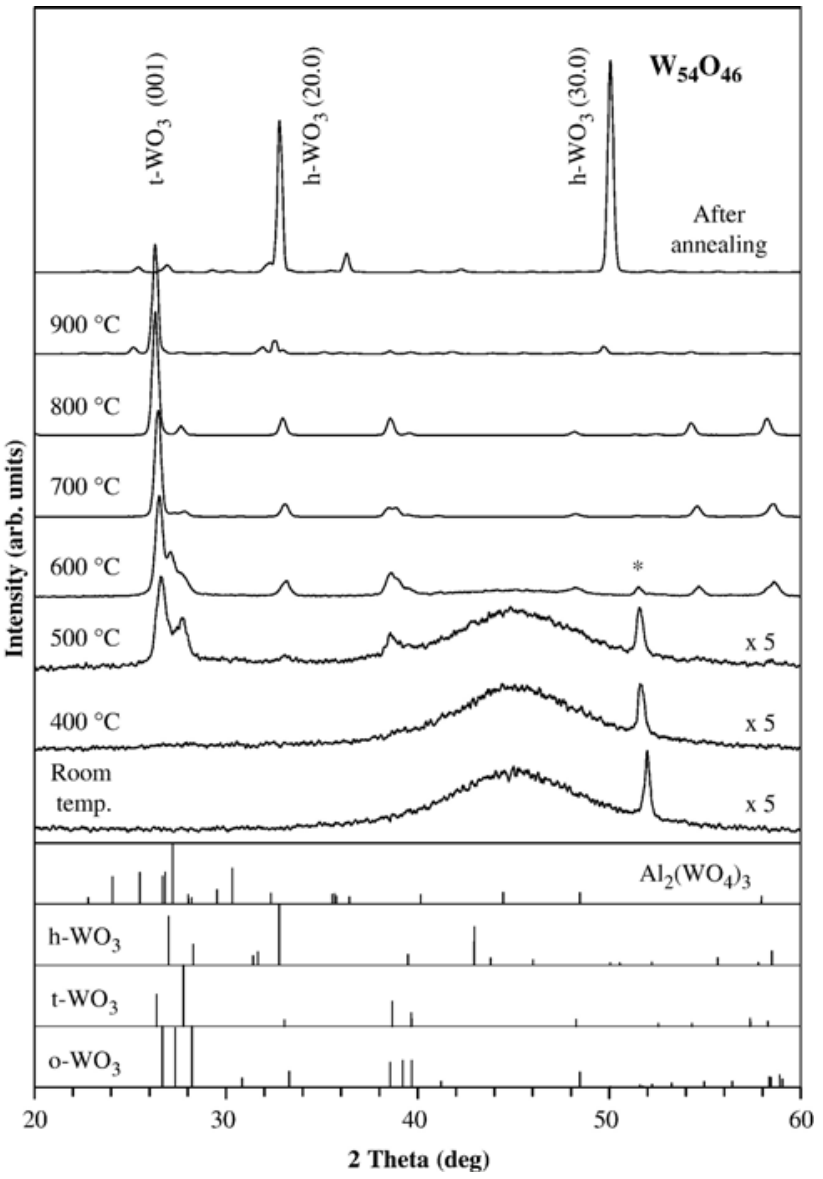

Fig. 5. Structural evolution of the $\mathrm{W}_{54} \mathrm{O}_{46}$ coating as a function of the temperature in normal atmosphere. Close to $2 \theta=52^{\circ}$ a substrate peak is visible.

The oxide phase formed at temperatures up to $700{ }^{\circ} \mathrm{C}$ can be indexed as o- $\mathrm{WO}_{3}$. At $500{ }^{\circ} \mathrm{C}$, only two main peaks could be observed in the XRD pattern in the region $25-30^{\circ}$ of these samples. All ICDD database cards of $\mathrm{W}_{n} \mathrm{O}_{3 n-2}$ or $\mathrm{W}_{n} \mathrm{O}_{3 n-1}$ have two peaks in this zone, suggesting that the crystallized phase could be attributed to these oxides. However, the small peak centred at $2 \theta=33^{\circ}$, does not belong to these ICDD cards but to $\mathrm{WO}_{3}$ phases which make that suggestion untenable. Initially, the temptation was to index the XRD pattern to the tetragonal $\mathrm{WO}_{3}$, the only form having only two peaks in the region 25$30^{\circ}$. However, this phase is only stable at temperatures higher than $740{ }^{\circ} \mathrm{C}$, and there is every chance that the correct phase is $\mathrm{o}-\mathrm{WO}_{3}$. This was confirmed by the peak's deconvolution of the pattern since a third peak has to be added in that region to absolutely fit the XRD pattern. In conclusion, the structure must be orthorhombic $\mathrm{WO}_{3}$ with a (002) preferential orientation at $500{ }^{\circ} \mathrm{C}$, the $(020)$ being very close to the $(200)$ reflection. At $600{ }^{\circ} \mathrm{C}$ the structure remains with the same $(002)$ preferential orientation but with (020) winning intensity in comparison to (200).

According to the analysis performed in protective atmosphere, at $700{ }^{\circ} \mathrm{C}$ the quasi-amorphous structure crystallized as equilibrium phases. As in room atmosphere all the amorphous structure disappeared at $600{ }^{\circ} \mathrm{C}$ and only o- $\mathrm{WO}_{3}$ phase was detected. Thus, it can be concluded that the oxidation of the coatings took place even before they changed their as-deposited structure, i.e. $\mathrm{O}$ was incorporated until $\mathrm{WO}_{3}$ stoichiometry was reached, meaning that the first crystalline phase detected during the annealing was o- $\mathrm{WO}_{3}$.

At $800{ }^{\circ} \mathrm{C}, \mathrm{t}-\mathrm{WO}_{3}$ with $(001)$ orientation was detected following the equilibrium evolution of the $\mathrm{W}$-Oxide. At $900{ }^{\circ} \mathrm{C}$, peaks corresponding to the $\mathrm{A}_{2}\left(\mathrm{WO}_{4}\right)_{3}$ are visible (see Section 3.2.1) as a result of the inter-diffusion of substrate elements. However, the peaks corresponding to the tungsten oxides changed to the hexagonal $\mathrm{WO}_{3}$ structure $\left(\mathrm{h}-\mathrm{WO}_{3}, \mathrm{ICDD}\right.$ card nr. 85-2459). The $\mathrm{h}-\mathrm{WO}_{3}$ phase is probably a result of the influence of the experimental settings. The analysis was done at room atmosphere with $\sim 50 \%$ of humidity and these conditions promote the stabilization of $\mathrm{h}-\mathrm{WO}_{3}$ structure [8]. The $\mathrm{h}-\mathrm{WO}_{3}$ phase exhibited (00.2) orientation at $900{ }^{\circ} \mathrm{C}$ and (10.0) orientation after the cooling down to room temperature.

\subsubsection{Coatings $W_{100}$ and $W_{90} O_{10}$}

Since $\mathrm{W}_{100}$ and $\mathrm{W}_{90} \mathrm{O}_{10}$ coatings exhibited a crystalline structure at room temperature, the structural analysis was only performed in room atmosphere in order to investigate the oxidation process at elevated temperatures. This study will be completed by the analysis of the mass variation (weight gain) as a function of the temperature measured by thermogravimetric

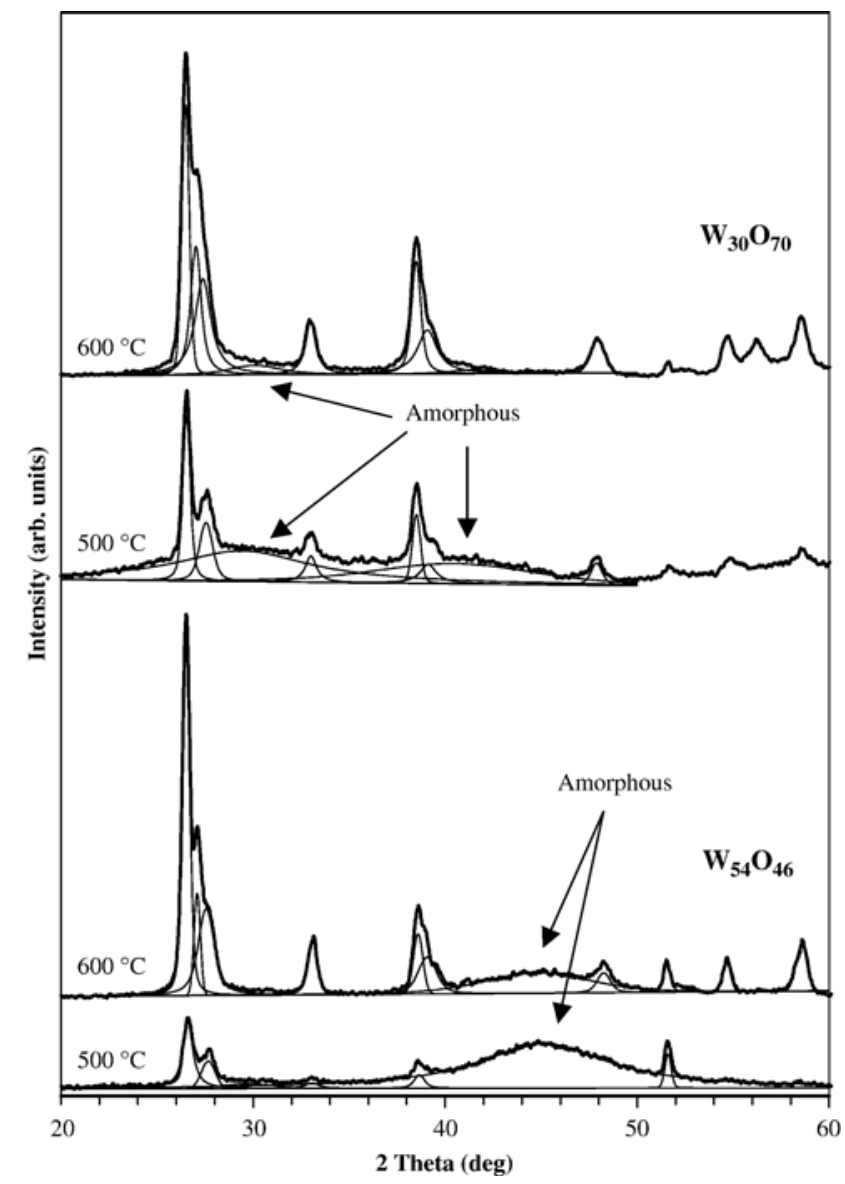

Fig. 6. Peak deconvolution of the XRD patterns of the samples $\mathrm{W}_{30} \mathrm{O}_{70}$ and $\mathrm{W}_{54} \mathrm{O}_{46}$ at 500 and $600{ }^{\circ} \mathrm{C}$, showing the amorphous and the crystalline parts of the XRD patterns. 


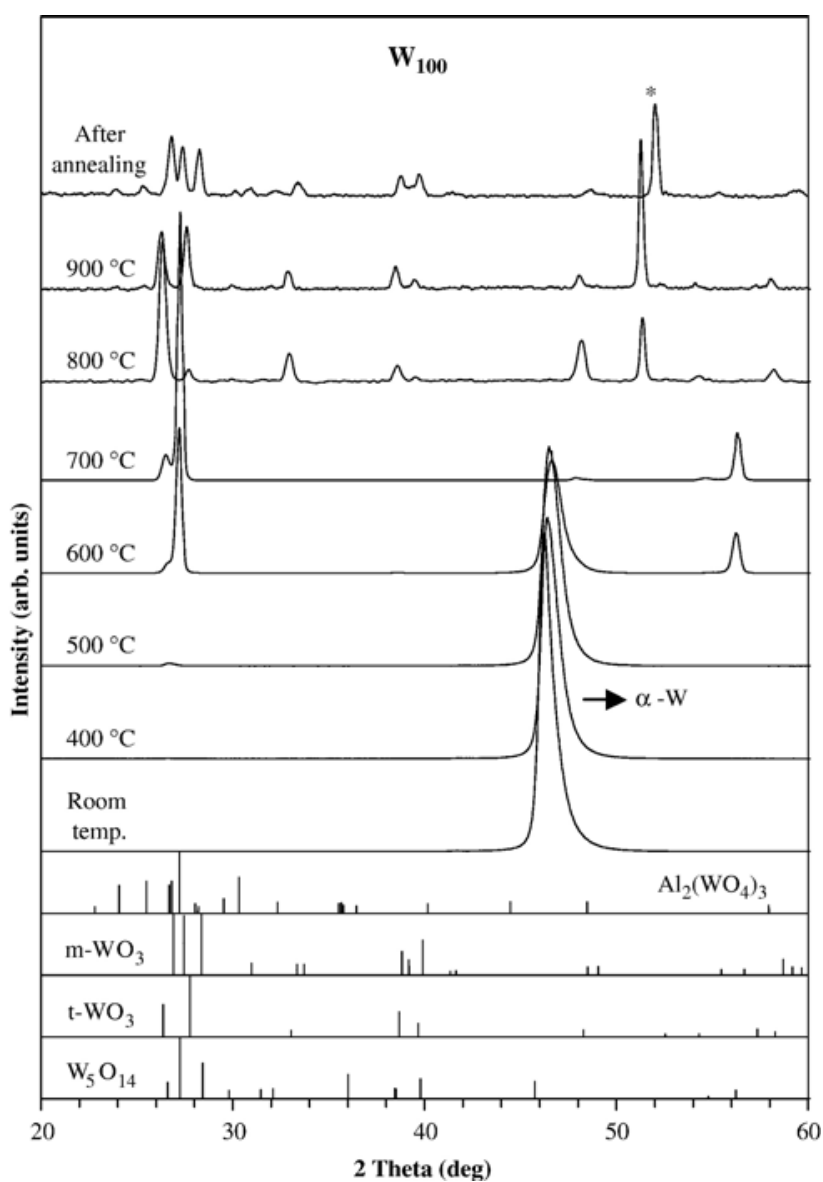

Fig. 7. Structural evolution of the $\mathrm{W}_{100}$ coating as a function of the temperature in normal atmosphere.

method, a process now underway [18]. Nevertheless, the oxidation analysis of pure tungsten films can be found in Ref. [19].

The structure of these coatings at room temperature is $\alpha-\mathrm{W}$ with (110) preferential orientation and a mixture of $\alpha-\mathrm{W}$ and $\beta-\mathrm{W}_{3} \mathrm{O}$ for $\mathrm{W}_{100}$ and $\mathrm{W}_{90} \mathrm{O}_{10}$, coatings, respectively (Figs. 7 and 8). The structure is stable up to $500{ }^{\circ} \mathrm{C}$, with the exception of the vestiges of oxide peaks close to $2 \theta=26^{\circ}$ detected at $500^{\circ} \mathrm{C}$. The intensity of these peaks significantly increased at $600^{\circ} \mathrm{C}$. Thus, the XRD patterns of both samples exhibit at $600{ }^{\circ} \mathrm{C}$ a mixture of an oxide phase (formed at 500 and reinforced at $600{ }^{\circ} \mathrm{C}$ ) and a residual crystalline phase of the as-sputtered coatings. All the as-deposited part disappeared completely at $700{ }^{\circ} \mathrm{C}$.

In case of $\mathrm{W}_{90} \mathrm{O}_{10}$ coating, the oxide phase at $600{ }^{\circ} \mathrm{C}$ is the $\mathrm{o}-\mathrm{WO}_{3}$ form. The structure evolution for higher temperatures follows that of $\mathrm{W}_{25} \mathrm{O}_{75}$ sample, i.e. change to t- $\mathrm{WO}_{3}$ at $800{ }^{\circ} \mathrm{C}$ and inter-diffusion at $900{ }^{\circ} \mathrm{C} . \mathrm{W}_{100}$ sample showed a somewhat more complicated evolution. In fact, the first formed oxide has a sub- $\mathrm{WO}_{3}$ composition and is strongly oriented. The XRD pattern at $700{ }^{\circ} \mathrm{C}$ shows peaks corresponding to the tetragonal $\mathrm{W}_{5} \mathrm{O}_{14}$ phase (only the (600) and (001) reflections are visible). At $800{ }^{\circ} \mathrm{C}$ the generated phase is $\mathrm{t}-\mathrm{WO}_{3}$, and a substrate peak could be detected at $2 \theta$ close to $51.4^{\circ}$. The presence of this peak is a consequence of the mechanical instability of the oxide layer

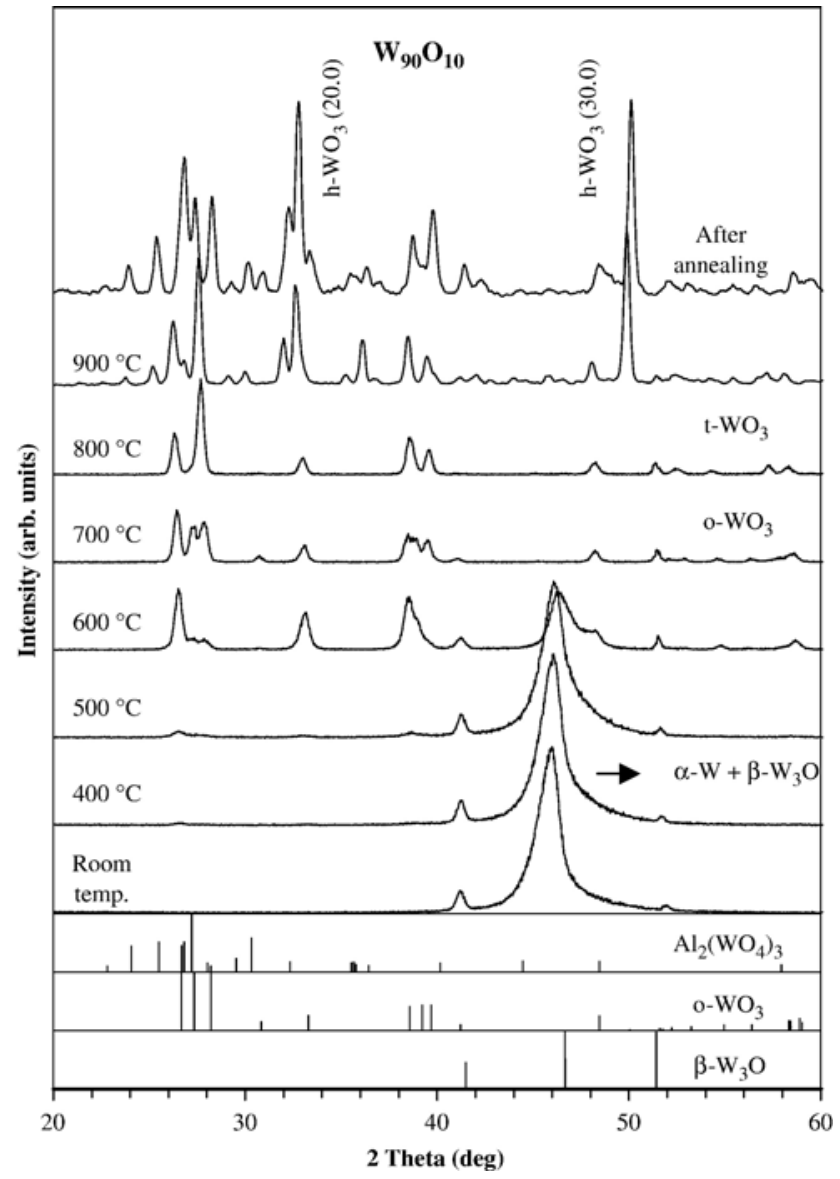

Fig. 8. Structural evolution of the $\mathrm{W}_{90} \mathrm{O}_{10}$ coating as a function of the temperature in normal atmosphere.

and its flaking off of the coated sample. This behaviour is described somewhere [18] showing that the flaking off starts at a temperature close to $740{ }^{\circ} \mathrm{C}$. As a conclusion, the growth evolution of the oxide phase and the oxidation process for the sputtered coatings deficient in oxygen can be considered to take place layer by layer, i.e. the surface of the coatings in

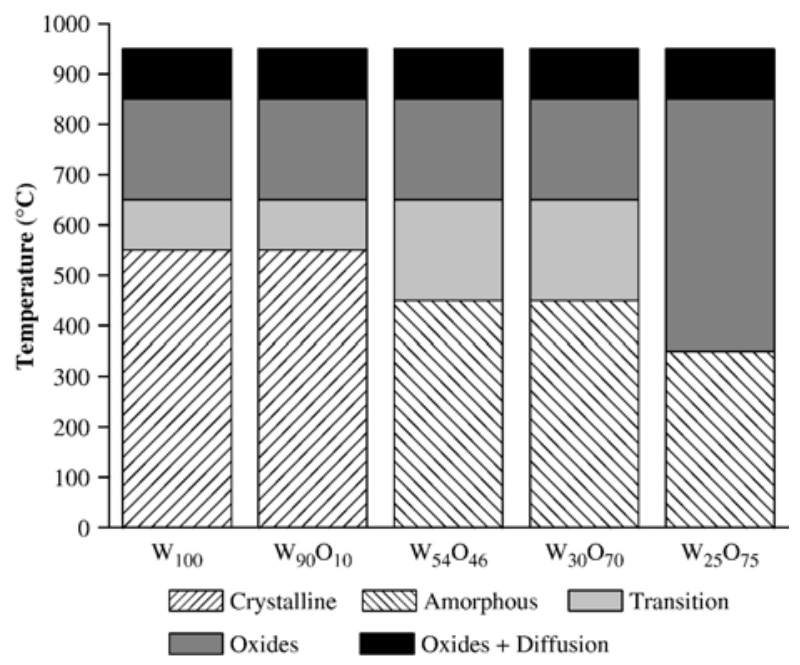

Fig. 9. Summary of the structural evolution of the studied samples as a function of the temperature. 
contact with the atmosphere forms a sub-oxide that will grow to a $\mathrm{WO}_{3}$ phase. At the same time a sub-layer starts to oxidize from the sputtered coating and, so, in the range of 600 and $700{ }^{\circ} \mathrm{C}$, the coating is composed of three layers, from the substrate up: i) the unoxidized sputtered coating, ii) the suboxide layer and iii) the $\mathrm{WO}_{3}$ top layer.

\section{Conclusions}

The structural stability of tungsten oxide thin films deposited by $\mathrm{DC}$ magnetron sputtering in $\mathrm{Ar}-\mathrm{O}_{2}$ reactive atmosphere was studied. With increasing temperatures two reactions in the coating can occur: crystallization (for the amorphous films) or phase transformation and oxidation.

Different chemical compositions were studied as follows: $\mathrm{W}_{100}, \mathrm{~W}_{90} \mathrm{O}_{10}, \mathrm{~W}_{54} \mathrm{O}_{46}, \mathrm{~W}_{30} \mathrm{O}_{70}$ and $\mathrm{W}_{25} \mathrm{O}_{75}$. The structure of these coatings at room temperature was a function of the oxygen content: $\alpha-\mathrm{W}$ and $\alpha-\mathrm{W}+\beta-\mathrm{W}_{3} \mathrm{O}$; amorphous and nanocrystalline phases were developed for coatings with low, medium and high oxygen content. Fig. 9 summarizes the main structural evolution. As the temperature increased, generally up to $500^{\circ} \mathrm{C}$, no alteration was registered in the as-deposited structure except $\mathrm{W}_{25} \mathrm{O}_{75}$ sample that changes to o- $\mathrm{WO}_{3}$ at $400{ }^{\circ} \mathrm{C}$. The structure evolution of $\mathrm{W}_{25} \mathrm{O}_{75}$ sample with increasing temperature is in accordance with the phase diagram and, at $900{ }^{\circ} \mathrm{C}$, interdiffusion between the film and the substrate occurs forming the $\mathrm{Al}_{2}\left(\mathrm{WO}_{4}\right)_{3}$ phase. O-deficient $\mathrm{WO}_{3}$ coatings tested in normal atmosphere start to oxidize at $600{ }^{\circ} \mathrm{C}$ and at $700{ }^{\circ} \mathrm{C}$ no vestiges of the as-deposited structure were observed. Testing in protective atmosphere showed that the beginning of the crystallization occurs at $700{ }^{\circ} \mathrm{C}$ and follows the phase diagram, $\beta-\mathrm{W}+\mathrm{WO}_{2}$ and $\mathrm{WO}_{2}+\mathrm{W}_{18} \mathrm{O}_{49}$ for $\mathrm{W}_{54} \mathrm{O}_{46}$ and $\mathrm{W}_{30} \mathrm{O}_{70}$, respectively. Low $\mathrm{O}$-content films start to oxidize at $500{ }^{\circ} \mathrm{C}$. After annealing at $700{ }^{\circ} \mathrm{C}$ all the initial as-deposited structure disappears.

This study will be completed with the study of the oxidation mechanisms, which is now underway.

\section{Acknowledgements}

This work was supported by the European Union through the NMP3-CT-2003-505948 project "HARDECOAT" and by the "Fundação para a Ciência e Tecnologia" of Portugal through the POCI/V.5/A0034/2005 project and the PhD Scholarship SFRH/ BD/16528/2004 attributed to the author Parreira.

\section{References}

[1] C.G. Granqvist, Sol. Energy Mater. Sol. Cells 60 (2000) 201.

[2] C.-J. Jin, T. Yamazaki, Y. Shirai, T. Yoshizawa, T. Kikuta, N. Nakatani, H. Takeda, Thin Solid Films 474 (2005) 255.

[3] C. Baruffaldi, S. Cattarin, M. Musiani, Electrochim. Acta 48 (2003) 3921.

[4] R. Andreani, E. Diegele, R. Laesser, B. van der Schaaf, J. Nucl. Mater. 329-333 (2004) 20.

[5] S.V.N. Naidu, P.R. Rao, Phase Diagrams of Binary Tungsten Alloys, Indian Institute of Metals, Calcutta, 1991.

[6] M. Gillet, K. Masek, E. Gillet, Surf. Sci. 566-568 (2004) 384.

[7] A. Al Mohamed, M. Gillet, Thin Solid Films 408 (2002) 302.

[8] O.Y. Khyzhun, Y.M. Solonin, V.D. Dobrovolsky, J. Alloys Compd. 320 (2001) 1.

[9] Y.G. Shen, Y.W. Mai, Mater. Sci. Eng., A Struct. Mater.: Prop. Microstruct. Process. 284 (2000) 176.

[10] N.M.G. Parreira, N.J.M. Carvalho, A. Cavaleiro, Thin Solid Films 510 (2006) 191.

[11] E. Lugscheider, O. Knotek, K. Bobzin, S. Bärwulf, Surf. Coat. Technol. $133-134$ (2000) 362.

[12] Powder Diffraction File, Joint Committee on Power Diffraction Standards, ASTM, Philadelphia, PA, 2000.

[13] N.M.G. Parreira, T. Polcar, A. Cavaleiro, Surf. Coat. Technol. 201 (2007) 5481.

[14] C. Suryanarayana, Non-equilibrium Processing of Materials, vol. 2, Pergamon, Oxford, 1999.

[15] C. Suryanarayana, M.G. Norton, X-Ray Diffraction - a Practical Approach, Plenum Press, New York, 1998.

[16] N. Garg, V. Panchal, A.K. Tyagi, S. Sharma, J. Solid State Chem. 178 (2005) 998.

[17] V.K. Tolpygo, D.R. Clarke, Acta Mater. 46 (1998) 5153.

[18] N.M.G. Parreira, C. Louro, A. Cavaleiro, Study of the thermal oxidation stability of tungsten oxide coatings (in preparation).

[19] C. Louro, A. Cavaleiro, J. Electrochem. Soc. 144 (1997) 259. 